\title{
Health-Related Factors Associated with Mode of Travel to Work
}

\author{
Melissa Bopp, ${ }^{1}$ Andrew T. Kaczynski, ${ }^{2}$ and Matthew E. Campbell ${ }^{1}$ \\ ${ }^{1}$ Department of Kinesiology, The Pennsylvania State University, 268R Recreation Building, University Park, PA 16802, USA \\ ${ }^{2}$ Department of Health Promotion, Education and Behavior, Arnold School of Public Health, Prevention Research Center, \\ University of South Carolina, Columbia, SC 29208, USA \\ Correspondence should be addressed to Melissa Bopp; mjb73@psu.edu
}

Received 5 December 2012; Accepted 24 January 2013

Academic Editor: Li Ming Wen

Copyright (C) 2013 Melissa Bopp et al. This is an open access article distributed under the Creative Commons Attribution License, which permits unrestricted use, distribution, and reproduction in any medium, provided the original work is properly cited.

\begin{abstract}
Active commuting (AC) to the workplace is a potential strategy for incorporating physical activity into daily life and is associated with health benefits. This study examined the association between health-related factors and mode of travel to the workplace. Methods. A volunteer convenience sample of employed adults completed an online survey regarding demographics, healthrelated factors, and the number of times/week walking, biking, driving, and using public transit to work (dichotomized as no walk/bike/drive/PT and walk/bike/drive/PT $1+x /$ week). Logistic regression was used to predict the likelihood of each mode of transport and meeting PA recommendations from AC according to demographics and health-related factors. Results. The sample ( $n=1175)$ was aged $43.5 \pm 11.4$ years and was primarily White $(92.7 \%)$ and female $(67.9 \%)$. Respondents reported walking $(7.3 \%)$, biking (14.4\%), taking public transit (20.3\%), and driving (78.3\%) to work at least one time/week. Among those reporting AC, 9.6\% met PA recommendations from AC alone. Mode of travel to work was associated with several demographic and healthrelated factors, including age, number of chronic diseases, weight status, and AC beliefs. Discussion. Mode of transportation to the workplace and health-related factors such as disease or weight status should be considered in future interventions targeting AC.
\end{abstract}

\section{Introduction}

The economic cost of preventable chronic disease in the United States is substantial, with the direct and indirect costs associated with cancer, cardiovascular disease, diabetes, mental health disorders, and pulmonary conditions estimated at more than \$1 trillion for the general population in 2003. Among employed adults, much of this economic burden is shouldered by employers in terms of private health insurance expenditures and lost productivity, with the costs associated with chronic disease nearing $\$ 465$ billion [1]. The visionary initiative targeting population level health is found in the US Department of Health and Human Services' Healthy People 2020 and includes goals of attaining high-quality, longer lives free of preventable disease and premature death [2]. This document includes goals and objectives focused on changing health behaviors that contribute to chronic disease morbidity and mortality, including specifically improving rates of physical activity participation along with environmental and policy approaches aimed at supporting this behavior across the lifespan.
Evidence outlining the benefits of regular physical activity participation for the prevention of chronic disease and premature mortality is substantial $[3,4]$. Epidemiological and clinical trials have documented the benefits of physical activity in preventing diabetes and metabolic disorders [58], cardiovascular disease [9-11], certain cancers [12-16], and mental health disorders [17-19]. The majority of these studies include data on all forms of physical activity (leisuretime, occupational, and transportation related). When specifically examining the health effects of transportation-related physical activity to work, known as active commuting (AC), data from epidemiological surveys have found relationships between active travel and a lesser presence of self-reported obesity [20-22] and a reduced risk of cardiovascular disease and all-cause mortality [23-26]. Despite these known benefits of active transport, in the United States, rates of AC remain low (3\% reporting walking to work, $<1 \%$ report biking to work), especially in comparison to other countries (e.g., The Netherlands: $25 \%$ of trips are made by bicycle) [27-29].

Recent research has addressed individual, social, and environmental factors associated with AC to work. Some 
documented correlates of AC include demographics (age, gender, income, and race/ethnicity) [30, 31], psychosocial (self-efficacy, behavioral beliefs, attitudes, and intention) [3235], and environmental influences (traffic, walkable and bikeable features, safety, and convenient public transport close to the workplace) [36-41]. However, few, if any, studies have focused in much depth on how diverse health-related factors are associated with AC [42], despite the acknowledgment that health is a prime determinant, motivator, and outcome of AC [25]. Moreover, the impact of health-related influences on specific modes of travel (e.g., walking, biking, transit, and driving) has received even less attention. Additionally, few studies have explored the extent to which AC provides sufficient opportunity to achieve recommended levels of physical activity that are adequate to achieve health benefits [43-45]. Moreover, to the extent that this is possible, what are the characteristics of individuals who engage in enough AC to meet physical activity recommendations?

Given these considerations, the purpose of this study was twofold. Our primary aim was to examine the relationship between numerous demographic and health-related factors and mode of travel to work (walking, biking, driving, and public transit). The secondary aim of the study was to examine the health-related factors associated with achieving current public health recommended levels of physical activity [46] via AC.

\section{Methods}

2.1. Survey Design. This cross-sectional survey was delivered online from June to December 2011 using Qualtrics (Provo, UT) and was approved by the Pennsylvania State University Institutional Review Board.

2.2. Participants and Recruitment. To be eligible, participants had to be over the age of 18 years, employed fullor part-time outside of the home, and physically able to walk or bike. Recruitment was focused in the mid-Atlantic region of the USA (PA, OH, WV, MD, NJ, and DE). The primary recruitment strategy involved visiting the websites of large employers (e.g., K-12 school districts, local/county government, private businesses, and universities/colleges) in medium to large cities for employee email addresses and subsequently contacting the employees directly with an email invitation. In cases where employee email addresses were not available, we contacted employers directly and asked them to distribute an electronic invitation to participate in the survey via listserv, e-newsletter, or mass email to their employees. Among employers contacted directly $(n=142)$, two employers refused to send out an email invitation, 84 did not respond in any way, and 56 sent out a recruitment invitation. Recruitment of participants is displayed in Figure 1.

\subsection{Measures}

2.3.1. Commuting Patterns. Participants were asked to reflect on the previous month and report the average number of times per week in the last month that they walked, biked, drove, and took public transportation (where available) to

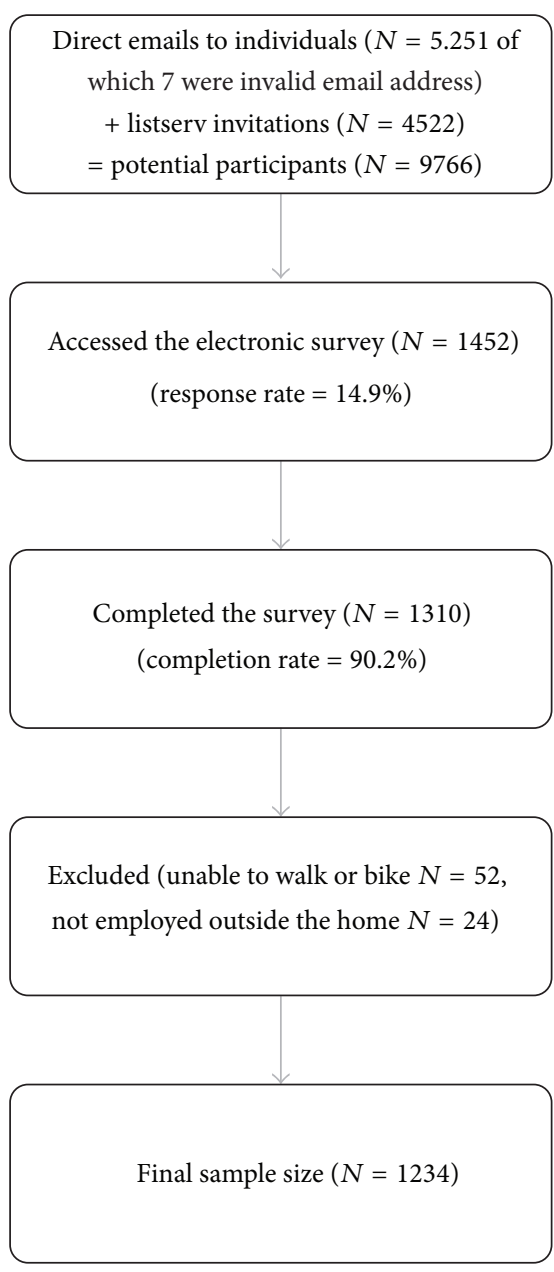

FIGURE 1: Participant recruitment.

and from work. For each mode of travel, a dichotomized variable was created to indicate no travel by the mode of travel or travel via the mode one or more times per week. Public transportation ridership was only considered among those who had public transit available to them as determined by self-report of public transit availability in their community $(n=748)$. Respondents also indicated the perceived number of minutes it would take them to walk and bike to work using one item for each mode.

2.3.2. Demographics and Health Outcomes. Participants reported their age, sex, race/ethnicity (collapsed into nonHispanic White, non-Hispanic Black, and other racial/ethnic groups), and income level. Participants responded (yes/no) if they had any cardiovascular/pulmonary disease (heart disease, high blood pressure, elevated cholesterol, and chronic obstructive pulmonary disease), metabolic disease (diabetes, liver, or thyroid disease), musculoskeletal disease (arthritis, osteoporosis), or depression, and a total number of chronic diseases was calculated. Diseases were then collapsed into the four categories and dichotomized (e.g., yes/no for reporting a metabolic disease). Individuals were also asked to report their height and weight for body mass 
index (BMI) calculations (weight in $\mathrm{kg} /$ (height in meters) $^{2}$ ). Respondents also rated their current health status from 1 (poor) to 5 (excellent). To determine if individuals were meeting current physical activity recommendations (at least 150 minutes/week of moderate intensity physical activity) [46] from their AC participation, the number of trips per week walking and biking were multiplied by the amount of time they reported for a walk or bike trip to work. The total number of minutes of AC time was calculated and was then dichotomized as meeting recommendations via active commuting (+150 minutes/week of active travel to work) or not meeting recommendations.

2.3.3. Perceived Health Benefits of AC. Respondents indicated their agreement with eight statements related to physical or mental health benefits of AC (e.g., AC helps me control my weight; AC can help me to relieve stress) using a 7-point Likert scale $(1=$ completely disagree to $7=$ completely agree $)$. A summed score was computed for all 8 items. This scale was based on a previously-tested measure [47] and showed excellent reliability in the present sample $(\alpha=0.89)$.

2.4. Statistical Analyses. Basic descriptives and frequencies were used to describe the sample. To examine the primary aim, for each mode of travel, separate univariate logistic regression models were used to predict the likelihood of walking, biking, driving, and public transit use at least once per week according to demographics and health-related factors (age, sex, income, race/ethnicity, chronic disease presence, perceived health status, and perceived health benefits of AC). Factors significantly associated with walking, biking, driving, and use of public transit were examined simultaneously in four multivariate logistic regression models and the Nagelkerke $R^{2}$ was calculated for each of the full models to examine the factors associated with each mode of travel. To address the secondary aim, the likelihood of meeting physical activity recommendations via $\mathrm{AC}$ was examined via univariate logistic regression with the same demographics and healthrelated factors and then a full model with significant factors was performed. All analyses were performed using SPSS 20.0 (Armonk, NY) and significance levels were set at $P<0.05$.

\section{Results}

The demographics of the sample are shown in Table 1. Participants were primarily non-Hispanic White (92.1\%), female $(68.3 \%)$, and had a high (over \$60,000) income level (63.2\%). The mean age of respondents was 43.8 years $($ s.d. $=11.4$ ) and slightly more than half of respondents were overweight $(31.5 \%)$ or obese (19.5\%). Most individuals (78.3\%) reported driving to work one or more times/week and $20.3 \%$ reported using public transit, though relatively few reported walking $(7.3 \%)$ or biking $(14.4 \%)$ one or more times/week. Among those traveling using active methods, 9.6\% met physical activity recommendations via AC.

3.1. Walking to Work One or More Times/Week. Univariate influences on walking to work at least once per week are
TABLE 1: Characteristics of the sample $(n=1234)$.

\begin{tabular}{|c|c|c|}
\hline Variable & $n(\%)$ & Mean (SD) \\
\hline \multicolumn{3}{|l|}{ Demographic } \\
\hline Age & & $43.76(11.44)$ \\
\hline \multicolumn{3}{|l|}{ Sex } \\
\hline Male & $327(31.7)$ & \\
\hline Female & $706(68.3)$ & \\
\hline \multicolumn{3}{|l|}{ Income level } \\
\hline$<\$ 30 \mathrm{~K} /$ year & $55(5.5)$ & \\
\hline$\$ 30-60 \mathrm{~K} /$ year & $309(31.2)$ & \\
\hline$>\$ 60 \mathrm{~K} /$ year & $626(63.2)$ & \\
\hline \multicolumn{3}{|l|}{ Race/ethnicity } \\
\hline Non-Hispanic White & $941(92.1)$ & \\
\hline Non-Hispanic Black & $33(3.2)$ & \\
\hline All other racial/ethnic groups & $48(4.8)$ & \\
\hline \multicolumn{3}{|l|}{ Health related } \\
\hline Number of chronic disease & & $0.64(1.01)$ \\
\hline \multicolumn{3}{|l|}{ Reporting chronic disease } \\
\hline $\mathrm{CV}$ pulmonary disease & $286(21.8)$ & \\
\hline Metabolic disease & $133(10.2)$ & \\
\hline Musculoskeletal disease & $120(9.2)$ & \\
\hline Depression & $170(13.0)$ & \\
\hline \multicolumn{3}{|l|}{ Body mass index } \\
\hline Normal weight & $460(49.0)$ & \\
\hline Overweight & $296(31.5)$ & \\
\hline Obese & $183(19.5)$ & \\
\hline \multicolumn{3}{|l|}{ Psychological } \\
\hline $\begin{array}{l}\text { Perceived health status } \\
\text { (range 1-5) }\end{array}$ & & $3.68(0.81)$ \\
\hline $\begin{array}{l}\text { Perceived health benefits } \\
\text { (range } 8-56 \text { ) }\end{array}$ & & $44.04(7.91)$ \\
\hline \multicolumn{3}{|l|}{ Mode of travel to work } \\
\hline Walking one or more time/week & $95(7.3)$ & \\
\hline Biking one or more time/week & $188(14.4)$ & \\
\hline Driving one or more time/week & $1026(78.3)$ & \\
\hline $\begin{array}{l}\text { Public transit use one or more } \\
\text { time/week }\end{array}$ & $152(20.3)$ & \\
\hline
\end{tabular}

AC: active commuting.

found in the first columns of Table 2. Age was negatively related to being a walker ( $\mathrm{OR}=0.97,95 \% \mathrm{CI}=0.95-$ 0.99). Those from "other" racial/ethnic groups were more likely to walk ( $\mathrm{OR}=2.99,95 \% \mathrm{CI}=1.44-6.25)$ compared to non-Hispanic Whites. Better perceived health status was associated with being a walker $(\mathrm{OR}=1.64,95 \% \mathrm{CI}=1.24-2.17)$ and being in the obese weight category was associated with being a non-walker ( $\mathrm{OR}=0.46,95 \% \mathrm{CI}=0.23-0.93)$. The full model of significant correlates resulted in a Nagelkerke $R^{2}$ of 0.07 , with race ("other" racial/ethnic group $\mathrm{OR}=2.91$, $95 \% \mathrm{CI}=1.34-6.31)$, age $(\mathrm{OR}=0.97,95 \% \mathrm{CI}=0.95-0.99)$, 
TABLE 2: Univariate influences on walking, biking, driving, and taking public transit to work, meeting physical activity recommendations via active transport modes.

\begin{tabular}{|c|c|c|c|c|c|c|c|c|c|c|}
\hline \multirow[t]{2}{*}{ Variable } & \multicolumn{2}{|c|}{$\begin{array}{l}\text { Walking to work at } \\
\text { least } 1 \text { time/week }\end{array}$} & \multicolumn{2}{|c|}{$\begin{array}{l}\text { Biking to work at } \\
\text { least } 1 \text { time/week }\end{array}$} & \multicolumn{2}{|c|}{$\begin{array}{l}\text { Driving to work at } \\
\text { least } 1 \text { time/week }\end{array}$} & \multicolumn{2}{|c|}{$\begin{array}{l}\text { Public transit to } \\
\text { work at least } 1 \\
\text { time/week }\end{array}$} & \multicolumn{2}{|c|}{$\begin{array}{l}\text { Meeting physical } \\
\text { activity } \\
\text { recommendations } \\
\text { via active transport } \\
\text { modes }\end{array}$} \\
\hline & OR & $95 \%$ CI & OR & $95 \% \mathrm{CI}$ & OR & $95 \%$ CI & OR & $95 \%$ CI & OR & $95 \% \mathrm{CI}$ \\
\hline \multicolumn{11}{|l|}{ Demographic variables } \\
\hline Age & $0.97^{* *}$ & $0.95-0.99$ & $0.93^{* * *}$ & $0.92-0.95$ & $1.04^{* * *}$ & $1.03-1.06$ & $0.97^{* *}$ & $0.95-0.99$ & $0.93^{* * *}$ & $0.91-0.95$ \\
\hline \multicolumn{11}{|l|}{ Income } \\
\hline$<\$ 30,000 /$ year (referent) & 1 & & 1 & & 1 & & 1 & & 1 & \\
\hline$\$ 30,000-60,000 /$ year & 0.71 & $0.29-1.71$ & $0.38^{* *}$ & $0.20-0.71$ & 1.1 & $0.52-2.32$ & 0.67 & $0.32-1.41$ & $0.32^{* * *}$ & $0.17-0.63$ \\
\hline$>\$ 60,000 /$ year & 0.64 & $0.26-1.41$ & $0.33^{* * *}$ & $0.18-0.60$ & 1.94 & $0.94-4.05$ & $0.46^{*}$ & $0.23-0.93$ & $0.24^{* * *}$ & $0.13-0.45$ \\
\hline Sex: female (male referent) & 0.85 & $0.54-1.35$ & $0.31^{* * *}$ & $0.22-0.43$ & $2.88^{* * *}$ & $1.98-4.19$ & $0.60^{* *}$ & $0.41-0.87$ & $0.28^{* * *}$ & $0.19-0.41$ \\
\hline \multicolumn{11}{|l|}{ Race } \\
\hline $\begin{array}{l}\text { Non-Hispanic White } \\
\text { (referent) }\end{array}$ & 1 & & 1 & & 1 & & 1 & & 1 & \\
\hline Non-Hispanic Black & 0.73 & $0.17-3.13$ & 0.33 & $0.08-1.38$ & 0.91 & $0.31-2.64$ & 1.65 & $0.63-4.36$ & 0.19 & $0.04-1.92$ \\
\hline $\begin{array}{l}\text { All other racial/ethnic } \\
\text { groups }\end{array}$ & $2.99^{* *}$ & $1.44-6.25$ & $3.04^{* * *}$ & $1.65-5.59$ & $0.21^{* * *}$ & $0.11-0.39$ & $2.32^{*}$ & $1.17-4.60$ & $3.41^{* * *}$ & $1.77-6.57$ \\
\hline \multicolumn{11}{|l|}{ Health-related variables } \\
\hline Number of chronic disease & 0.96 & $0.77-1.18$ & $0.78^{*}$ & $0.65-0.94$ & $2.13^{* *}$ & $1.72-2.64$ & 1.03 & $0.88-1.22$ & $0.76^{*}$ & $0.61-0.96$ \\
\hline \multicolumn{11}{|l|}{$\begin{array}{l}\text { Reporting chronic disease } \\
\text { (no disease as referent) }\end{array}$} \\
\hline CV pulmonary disease & 0.98 & $0.59-1.63$ & 1.37 & $0.92-2.04$ & $3.37^{* * *}$ & $2.20-5.16$ & 0.88 & $0.58-1.33$ & $0.58^{*}$ & $0.34-0.97$ \\
\hline Metabolic disease & 0.58 & $0.25-1.35$ & $0.26^{* * *}$ & $0.11-0.60$ & $4.20^{* * *}$ & $2.11-8.37$ & 1.23 & $0.67-2.25$ & $0.58^{*}$ & $0.35-0.97$ \\
\hline Musculoskeletal disease & 1.1 & $0.52-2.33$ & 1.73 & $0.91-3.28$ & $3.29^{* * *}$ & $1.70-6.37$ & 1.21 & $0.66-2.21$ & $0.34^{*}$ & $0.14-0.85$ \\
\hline Depression & 1.28 & $0.72-2.28$ & 1.21 & $0.78-1.87$ & $2.75^{* * *}$ & $1.64-4.63$ & 0.68 & $0.44-1.09$ & 1.14 & $0.67-1.93$ \\
\hline \multicolumn{11}{|l|}{ Body mass index } \\
\hline Normal weight & 1 & & 1 & & 1 & & 1 & & 1 & \\
\hline Overweight & 0.77 & $0.47-1.27$ & $0.58^{* *}$ & $0.39-0.85$ & 1.34 & $0.88-2.04$ & 0.98 & $0.64-1.51$ & $0.62^{*}$ & $0.39-0.97$ \\
\hline Obese & $0.46^{*}$ & $0.23-0.93$ & $0.26^{* * *}$ & $0.14-0.47$ & $2.59^{* *}$ & $1.40-4.79$ & 0.77 & $0.44-1.34$ & $0.35^{* *}$ & $0.18-0.67$ \\
\hline \multicolumn{11}{|l|}{ Psychological variables } \\
\hline Perceived health status $^{\mathrm{a}}$ & $1.64^{* *}$ & $1.24-2.17$ & $1.98^{* * *}$ & $1.59-2.45$ & $0.63^{* * *}$ & $0.49-0.80$ & 0.87 & $0.69-1.11$ & $1.64^{* * *}$ & $1.28-2.11$ \\
\hline $\begin{array}{l}\text { Perceived health benefits of } \\
\text { AC }\end{array}$ & 1.03 & $0.99-1.06$ & $1.05^{* * *}$ & $1.03-1.08$ & 0.98 & $0.95-1.01$ & 0.99 & $0.97-1.02$ & $1.04^{* *}$ & $1.01-1.07$ \\
\hline
\end{tabular}

Note: ${ }^{*} P<0.05,{ }^{* *} P<0.01,{ }^{* * *} P<0.001,{ }^{\text {a }}$ scale ranges 1 (poor) to 5 (excellent), and AC: active commuting.

and perceived health status $(\mathrm{OR}=1.60,95 \% \mathrm{CI}=1.17-2.20)$ as significant predictors of walking to work.

3.2. Biking to Work One or More Times/Week. The univariate influences for biking to work are found in Table 2. Similar to those walking to work, age was negatively associated with being a biker $(\mathrm{OR}=0.93,95 \% \mathrm{CI}=0.92-0.95)$ and females were less likely to bike to work than males ( $\mathrm{OR}=0.31,95 \%$ $\mathrm{CI}=0.22-0.43)$. Higher income status was associated with being a non-biker, with both the $\$ 30,000-\$ 60,000$ groups $(\mathrm{OR}=0.38,95 \% \mathrm{CI}=0.20-0.71)$ and the $\$ 60,000$ and up group $(\mathrm{OR}=0.31,95 \% \mathrm{CI}=0.18-0.60)$ less likely to bike to work than the lowest income group $(<\$ 30,000 /$ year $)$. Those from "other" racial/ethnic groups were more likely to bike
$(\mathrm{OR}=3.04,95 \% \mathrm{CI}=1.65-5.59)$ compared to non-Hispanic Whites. A greater number of chronic diseases was associated with being a non-biker $(\mathrm{OR}=0.78,95 \% \mathrm{CI}=0.65-0.94)$ while better perceived health status was associated with biking $(\mathrm{OR}=1.98,95 \% \mathrm{CI}=1.59-2.45)$. Those reporting metabolic disease $(\mathrm{OR}=0.26,95 \% \mathrm{CI}=0.11-0.60)$, overweight $(\mathrm{OR}$ $=0.58,95 \% \mathrm{CI}=0.39-0.85)$, and obese status $(\mathrm{OR}=0.26$, $95 \% \mathrm{CI}=0.14-0.47)$ were less likely to report biking. Those with greater perceived health benefits of AC were more likely to be bikers $(\mathrm{OR}=1.05,95 \% \mathrm{CI}=1.03-1.08)$. A full multivariate model revealed a Nagelkerke $R^{2}$ of 0.27 , with race ("other" racial/ethnic group $\mathrm{OR}=2.40,95 \% \mathrm{CI}=1.09-5.30$ ), age $(\mathrm{OR}=0.93,95 \% \mathrm{CI}=0.92-0.95)$, income $(\$ 30,000-$ $60,000 /$ year $\mathrm{OR}=0.31,95 \% \mathrm{CI}=0.14-0.69 ;<\$ 60,000 /$ year 
$\mathrm{OR}=0.36,95 \% \mathrm{CI}=0.16-0.78)$, perceived health status ( $\mathrm{OR}$ $=1.95,95 \% \mathrm{CI}=1.47-2.61)$, and $\mathrm{AC}$ health beliefs $(\mathrm{OR}=1.05$, $95 \% \mathrm{CI}=1.02-1.08)$ as significant predictors.

3.3. Driving to Work One or More Times/Week. Univariate analyses for driving to work are displayed in Table 2. Older age was associated with driving one or more times per week $(\mathrm{OR}=1.04,95 \% \mathrm{CI}=1.03-1.06)$, and those from "other" racial/ethnic groups were less likely to be drivers compared with non-Hispanic Whites ( $\mathrm{OR}=0.21,95 \% \mathrm{CI}=0.11-0.39)$. Females were more likely to report driving compared to males $(\mathrm{OR}=2.88,95 \% \mathrm{CI}=1.98-4.19)$. A greater number of chronic diseases $(\mathrm{OR}=2.13,95 \% \mathrm{CI}=1.72-2.64)$ and poorer perceived health status $(\mathrm{OR}=0.63,95 \% \mathrm{CI}=0.49-0.80)$ were also associated with being a driver. Reporting cardiopulmonary disease $(\mathrm{OR}=3.37,95 \% \mathrm{CI}=2.20-5.16)$, metabolic disease $(\mathrm{OR}=4.20,95 \% \mathrm{CI}=2.11-8.37)$, musculoskeletal disease $(\mathrm{OR}=3.29,95 \% \mathrm{CI}=1.70-6.37)$, depression $(\mathrm{OR}=2.75,95 \%$ $\mathrm{CI}=1.64-4.63)$, or being overweight $(\mathrm{OR}=2.59,95 \% \mathrm{CI}=$ $1.40-4.79)$ was associated with being a driver. The full model resulted in a Nagelkerke $R^{2}$ value of 0.12 , with race ("other" racial/ethnic group $\mathrm{OR}=0.26,95 \% \mathrm{CI}=0.13-0.55)$, age $(\mathrm{OR}=1.03,95 \% \mathrm{CI}=1.01-1.05)$, and perceived health status $(\mathrm{OR}=0.62,95 \% \mathrm{CI}=0.46-0.84)$ as significant predictors.

3.4. Public Transportation One or More Times/Week. Table 2 outlines the univariate influences on public transportation use. Similar to walking and biking, younger age was associated with being a public transit rider to work (OR = $0.97,95 \% \mathrm{CI}=0.95-0.99)$. Those reporting a higher income were less likely to report public transit ridership compared with those at the lowest income level ( $\mathrm{OR}=0.46,95 \%$ $\mathrm{CI}=0.23-0.93)$. Females were less likely to be transit riders compared to males $(\mathrm{OR}=0.60,95 \% \mathrm{CI}=0.41-0.87)$, and those from "other" racial/ethnic groups were more likely to use transit compared with non-Hispanic Whites $(\mathrm{OR}=2.32$, $95 \% \mathrm{CI}=1.17-4.60)$. There were no health-related variables significantly associated with public transit use. The full model had a Nagelkerke $R^{2}$ of 0.06 , with age (OR $=0.97,95 \% \mathrm{CI}=$ $0.95-0.99)$ as a significant predictor.

3.5. Meeting Physical Activity Recommendations via Active Commuting. The univariate analyses examining influences on meeting physical activity recommendations via $\mathrm{AC}$ are found in Table 2. Younger age was associated with meeting recommendations from $\mathrm{AC}(\mathrm{OR}=0.93,95 \% \mathrm{CI}=0.91-0.95)$. Those earning $\$ 30,000-60,000 /$ year $(\mathrm{OR}=0.32,95 \% \mathrm{CI}=$ $0.17-0.63)$ and greater than $\$ 60,000 /$ year $(\mathrm{OR}=0.24,95 \%$ $\mathrm{CI}=0.13-0.45$ ) were less likely to meet recommendations via AC compared with those in lower income groups. Females were less likely to meet recommendations relative to males $(\mathrm{OR}=0.28,95 \% \mathrm{CI}=0.19-0.41)$ and those in the "other" racial/ethnic group were more likely to meet recommendations compared with non-Hispanic Whites $(\mathrm{OR}=3.41$, 95\% CI $=1.77-6.57)$. Participants reporting more chronic diseases $(\mathrm{OR}=0.76,95 \% \mathrm{CI}=0.61-0.96)$ and specifically cardiopulmonary $(\mathrm{OR}=0.58,95 \% \mathrm{CI}=0.34-0.97)$, metabolic $(\mathrm{OR}=0.58,95 \% \mathrm{CI}=0.35-0.97)$, or musculoskeletal disease $(\mathrm{OR}=0.34,95 \% \mathrm{CI}=0.14-0.85)$ were less likely to meet recommendations. Overweight $(\mathrm{OR}=0.62,95 \% \mathrm{CI}=0.39$ 0.97 ) and obese $(\mathrm{OR}=0.35,95 \% \mathrm{CI}=0.18-0.67)$ individuals were also less likely to meet recommendations from AC. Finally, those who perceived greater health benefits of AC $(\mathrm{OR}=1.04,95 \% \mathrm{CI}=1.01-1.07)$ and more positive personal health status $(\mathrm{OR}=1.64,95 \% \mathrm{CI}=1.28-2.11)$ were more likely to meet recommendations. The full model resulted in a Nagelkerke $R^{2}$ of 0.26 , with perceived health status $(\mathrm{OR}=$ 1.53 , 95\% CI $=1.11-2.12)$, age $(\mathrm{OR}=0.94,95 \% \mathrm{CI}=0.92-$ $0.96)$, higher income $(\$ 30,000-60,000 /$ year $\mathrm{OR}=0.29,95 \%$ $\mathrm{CI}=0.13-0.68$ and $<\$ 60,000 /$ year $\mathrm{OR}=0.26,95 \% \mathrm{CI}=0.11-$ $0.59)$, and female gender ( $\mathrm{OR}=0.24,95 \% \mathrm{CI}=0.15-0.39)$ as significant predictors.

\section{Discussion}

This study revealed a number of relationships between health-related outcomes and mode of travel to work. For the active transportation modes, there were a number of significant health-related influences while poorer health outcomes were associated with the more passive forms of travel. Understanding this relationship between choice of travel mode to work and health outcomes allows for the development of interventions to promote $\mathrm{AC}$, with considerations for some of the health-related concerns addressed with this study. Among those who were active enough using active transportation modes, the noted health-related influences have considerable implications for public health.

There is clear evidence that physical activity participation [3], and specifically AC, can result in positive health outcomes $[20,21,23,25]$. Other studies have also highlighted how continued physical activity participation and lifestyle choices can help to manage diabetes $[48,49]$ or cardiovascular disease [50-52] and help with cancer survivorship [53, 54]. In the current study, those with cardiopulmonary, metabolic and musculoskeletal disease, and depression were more likely to choose the more passive mode of travel, driving. Although these individuals are already impacted with these chronic conditions, the evidence suggests that increased physical activity can help with management of these diseases, and active travel could possibly contribute to achieving current public health recommendations for physical activity [46].

A small portion of participants in the current study reported meeting physical activity recommendations based on active transportation alone. Recent models attempting to understand the influences on physical activity participation have indicated that active transportation is an often overlooked method of accumulating recommended amounts of physical activity $[55,56]$. Data from Kaczynski and colleagues indicated that adults reporting walking or biking for transportation at least once per week was associated with meeting physical activity recommendations [45], similar to a study by Berrigan and colleagues [57]. Other studies by Yang et al. [42] and Sahlqvist et al. [44] found a positive relationship between $\mathrm{AC}$ and daily physical activity participation and other studies have confirmed that more time spent in cars is associated with less time for physical activity participation [58]. Using public transportation can often serve as a catalyst for encouraging physical activity; for example, studies have 
shown that using public transportation is associated with significant walking to and from transit $[43,59]$, and many individuals meet current physical activity recommendations through active transport to and from transit locations [43, 60]. Therefore, where feasible, public health campaigns may wish to encourage transit use over vehicular commuting, and this strategy and behavior may be more palatable to a large segment of the population who eschew the idea of biking and walking to work.

The majority of literature has focused on travel to work as a collapsed variable (e.g., walking and biking combined) and limited research as examined how specific modes of travel are related to health outcomes. A study examining the relationship between commuting and health outcomes in Sweden also found poorer health outcomes (sleep quality, everyday stress, and frequent illness) and perceived health associated with commuting via car [61]. Hemmingsson and colleagues [62] found that commuting via bicycle (but not walking) was associated with improved diabetes biomarkers among obese women. Frank and colleagues [63] also noted an elevated risk of obesity as time spent in cars increased, and time walking was associated with less obesity. Another study noted that switching to commuting by public transportation instead of a car increased energy expenditure and decreased body fat [64]. Zheng [65] also noted that those commuting by public transportation were $44.6 \%$ less likely to be overweight due to an increase in walking or biking associated with transit use. The present study adds to our understanding of how a variety of health-related factors and other demographic indicators are associated specifically with each of walking, biking, driving, and use of public transportation to work.

In the current study, race/ethnicity was a significant influence in several analyses. Limited research has addressed racial/ethnic differences in AC among adults, though a number of studies have noted different trends among youth traveling to school [66-68]. There is some evidence to suggest that there are differences in active transportation rates among adults $[42,57,69]$ though there is little mode-specific information available. Other studies have indicated that rates of leisure time physical activity are lower in ethnic minority groups, and household or occupational activity is higher [70-74]. This would suggest that some social or cultural differences associated with AC may exist that have not been well-explored. The results of this study add to the limited research in this area regarding mode choice to work and race/ethnicity.

Employee health is often a significant concern for employers, with absenteeism, productivity, and health insurance benefits representing substantial costs. Interventions and strategies targeting physical activity participation in worksite settings have noted positive cost effectiveness outcomes associated with behavior change among employees [7579]. Therein, there is notable interest in understanding all types of physical activity participation and influences among employed adults. As noted above, transportation related activity has many documented benefits and may be a timeeffective approach to including physical activity into one's day for busy, working adults. Lachapelle and Frank [60] noted that employer-sponsored transit passes were associated with increased physical activity participation and other research has shown that workplace supports for AC can be a significant influence on participation [37, 80]. Employers may benefit from developing supporting policies or programs to encourage active forms of travel with the long term goal of reduced chronic disease morbidity and mortality among employees, for example, enacting policies regarding a flexible dress code to allow for active travel or develop incentive programs to reward employees who walk or bike to work.

This study also revealed that older adults and those in poorer health are less likely to actively travel to work. These findings present some challenges for practitioners looking to target this behavior within this population. Additional research may be needed to determine what the specific barriers to AC are for these populations in order to effectively improve behavior. For example, some research has shown that sidewalks, a key piece of the active transportation infrastructure in many communities, are more lacking in quality in lower income areas [81]. This may be especially problematic for older adults and persons with mobility impairments. Additionally, intervention strategies targeting AC could draw on the abundance of evidence found in physical activity interventions tailored for older adults or clinical populations. Some of the strategies that could be translated into an intervention targeting older employees or employees with chronic conditions could include use of social support from coworkers or family, improving self-efficacy for AC, providing education on the benefits of $\mathrm{AC}$, enlisting healthcare providers' advice for increasing physical activity, use of selfmonitoring and self-regulatory skills, and creating activityfriendly environments and policies [82-86]. Behavior-change theory should also be applied to target known mediators of AC (e.g., self-efficacy, outcome expectations) and improve the effectiveness of interventions [87].

Although this study yielded a number of important insights into the relationship between mode of transportation and health outcomes, there are some noteworthy limitations. The convenience sampling strategy used in this study may not have recruited respondents who are representative of the larger population, though rates of AC were similar to many of the other studies cited. Though the response rate was also low, it was calculated conservatively, as we were unable to determine how many of our email invitations were channeled into "junk/spam" mailboxes, thereby remaining unread by potential respondents. The cross-sectional study also limits our ability to draw causal inferences between AC and health outcomes. Although significant evidence has indicated the importance of environmental-level variables, these were not examined in the current study; however additional analyses with these variables are found elsewhere [80]. It should also be noted that dichotomizing the mode of travel as none versus one or more trips per week may have resulted in frequent walkers and bikers being categorized with those who walk or bike infrequently. Although those who actively commute even a limited amount of time are likely to be more similar to employees who walk or bike to work a lot than those who do not actively commute at all, these categorization decisions could present some challenges with interpreting our findings. Finally, we used self-reported, unvalidated measures of AC 
behavior and health outcomes, which have limited objectivity. Future studies should use multiple measures of behavior and health outcomes to enhance the validity and reliability of the data.

Despite these limitations, this study contributes to the literature on how mode of travel to work is associated with health outcomes. Given the documented benefits associated with participation in physical activity and specifically AC, there is merit in examining the possible role these behaviors can contribute to reducing morbidity and mortality from the leading chronic diseases and associated healthcare expenditures. Community design and environmental supports, along with worksite programs and policies, can influence travel choices and should be considered as targets for interventions for improving population-level health.

\section{References}

[1] R. Devol and A. Bedroussian, An Unhealthy America: the Economic Burden of Chronic Disease. Charting a New Course to Save Lives and increase Productivity and Economic Growth, Milkin Institute, 2007.

[2] U.S. Department of Health and Human Services (USDHHS), Healthy People 2020, 2012.

[3] Physical Activity Guidelines Advisory Committee, "Physical activity guidelines advisory committee report," Tech. Rep., US Department of Health and Human Services, Washington, DC, USA, 2008.

[4] S. N. Blair and J. N. Morris, "Healthy hearts-and the universal benefits of being physically active: physical activity and health," Annals of Epidemiology, vol. 19, no. 4, pp. 253-256, 2009.

[5] S. M. Grundy, "Pre-diabetes, metabolic syndrome, and cardiovascular risk," Journal of the American College of Cardiology, vol. 59, no. 7, pp. 635-643, 2012.

[6] I. Hopper, B. Billah, M. Skiba, and H. Krum, "Prevention of diabetes and reduction in major cardiovascular events in studies of subjects with prediabetes: meta-analysis of randomised controlled clinical trials," European Journal of Cardiovascular Prevention and Rehabilitation, vol. 18, no. 6, pp. 813-823, 2011.

[7] A. Ramachandran and C. Snehalatha, "Diabetes prevention programs," Medical Clinics of North America, vol. 95, no. 2, pp. 353-372, 2011.

[8] W. C. Knowler, E. Barrett-Connor, S. E. Fowler et al., "Reduction in the incidence of type 2 diabetes with lifestyle intervention or metformin," The New England Journal of Medicine, vol. 346, no. 6, pp. 393-403, 2002.

[9] L. Worrall-Carter, C. Ski, E. Scruth, M. Campbell, and K. Page, "Systematic review of cardiovascular disease in women: assessing the risk," Nursing \& Health Sciences, vol. 13, no. 4, pp. 529-535, 2011.

[10] S. S. Bassuk and J. E. Manson, "Physical activity and cardiovascular disease prevention in women: a review of the epidemiologic evidence," Nutrition, Metabolism and Cardiovascular Diseases, vol. 20, no. 6, pp. 467-473, 2010.

[11] H. M. Ahmed, M. J. Blaha, K. Nasir, J. J. Rivera, and R. S. Blumenthal, "Effects of physical activity on cardiovascular disease," American Journal of Cardiology, vol. 109, no. 2, pp. 288295, 2012.

[12] S. Zaslau, R. Jansen, D. R. Riggs, B. J. Jackson, and R. W. Bryner, "Possible prevention and treatment of prostate cancer by exercise," The West Virginia Medical Journal, vol. 108, no. 3, pp. 42-47, 2012.

[13] P. D. Loprinzi, B. J. Cardinal, K. Winters-Stone, E. Smit, and C. L. Loprinzi, "Physical activity and the risk of breast cancer recurrence: a literature review," Oncology Nursing Forum, vol. 39, no. 3, pp. 269-274, 2012.

[14] F. Anzuini, A. Battistella, and A. Izzotti, "Physical activity and cancer prevention: a review of current evidence and biological mechanisms," Journal of Preventive Medicine and Hygiene, vol. 52, no. 4, pp. 174-180, 2011.

[15] H. K. Na and S. Oliynyk, "Effects of physical activity on cancer prevention," Annals of the New York Academy of Sciences, vol. 1229, no. 1, pp. 176-183, 2011.

[16] K. Y. Wolin, Y. Yan, G. A. Colditz, and I. M. Lee, "Physical activity and colon cancer prevention: a meta-analysis," British Journal of Cancer, vol. 100, no. 4, pp. 611-616, 2009.

[17] A. L. Dunn and J. S. Jewell, "The effect of exercise on mental health," Current Sports Medicine Reports, vol. 9, no. 4, pp. 202207,2010

[18] E. W. Martinsen, "Physical activity in the prevention and treatment of anxiety and depression," Nordic Journal of Psychiatry, vol. 62 , no. 47 , pp. 25-29, 2008.

[19] A. Ströhle, "Physical activity, exercise, depression and anxiety disorders," Journal of Neural Transmission, vol. 116, no. 6, pp. 777-784, 2009.

[20] J. Pucher, R. Buehler, D. R. Bassett, and A. L. Dannenberg, "Walking and cycling to health: a comparative analysis of city, state, and international data," American Journal of Public Health, vol. 100, no. 10, pp. 1986-1992, 2010.

[21] M. Lindström, "Means of transportation to work and overweight and obesity: a population-based study in southern Sweden," Preventive Medicine, vol. 46, no. 1, pp. 22-28, 2008.

[22] T. Sugiyama, D. Merom, M. Reeves, E. Leslie, and N. Owen, "Habitual active transport moderates the association of TV viewing time with body mass index," Journal of Physical Activity and Health, vol. 7, no. 1, pp. 11-16, 2010.

[23] M. Hamer and Y. Chida, "Active commuting and cardiovascular risk: A meta-analytic review," Preventive Medicine, vol. 46, no. 1, pp. 9-13, 2008 .

[24] L. Bo Andersen, P. Schnohr, M. Schroll, and H. Ole Hein, "Allcause mortality associated with physical activity during leisure time, work, sports, and cycling to work," Archives of Internal Medicine, vol. 160, no. 11, pp. 1621-1628, 2000.

[25] R. J. Shephard, "Is active commuting the answer to population health?” Sports Medicine, vol. 38, no. 9, pp. 751-758, 2008.

[26] G. L. Furie and M. M. Desai, "Active transportation and cardiovascular disease risk factors in U.S. Adults," American Journal of Preventive Medicine, vol. 43, no. 6, pp. 621-628, 2012.

[27] T. L. Hart, C. L. Craig, J. M. Griffiths et al., "Markers of sedentarism: the joint Canada/U.S. survey of health," Journal of Physical Activity and Health, vol. 8, no. 3, pp. 361-371, 2011.

[28] D. R. Bassett Jr., J. Pucher, R. Buehler, D. L. Thompson, and S. E. Crouter, "Walking, cycling, and obesity rates in Europe, North America and Australia," Journal of Physical Activity and Health, vol. 5, no. 6, pp. 795-814, 2008.

[29] P. S. Hu and T. R. Reuscher, Summary of Travel Trends: 2001 National Household Transportation Survey, U.S. Department of Transportation \& Federal Highway Adminstration, Washington, DC, USA, 2004.

[30] M. Bopp, A. T. Kaczynski, and P. Wittman, "Active commuting patterns at a large, midwestern college campus," The Journal of American College Health, vol. 59, no. 7, pp. 605-611, 2011. 
[31] M. Bopp, A. T. Kaczynski, and G. Besenyi, "Active commuting influences among adults," Preventive Medicine, vol. 54, no. 3-4, pp. 237-241, 2012.

[32] J. R. Panter, A. P. Jones, E. M. F. Van Sluijs, S. J. Griffin, and N. J. Wareham, "Environmental and psychological correlates of older adult's active commuting," Medicine and Science in Sports and Exercise, vol. 43, no. 7, pp. 1235-1243, 2011.

[33] M. Lemieux and G. Godin, "How well do cognitive and environmental variables predict active commuting?" International Journal of Behavioral Nutrition and Physical Activity, vol. 6, article no. 12, 2009.

[34] G. J. de Bruijn, S. P. J. Kremers, A. Singh, B. van den Putte, and W. van Mechelen, "Adult active transportation. Adding habit strength to the theory of planned behavior," American Journal of Preventive Medicine, vol. 36, no. 3, pp. 189-194, 2009.

[35] M. Bopp, A. T. Kaczynski, and P. Wittman, "The relationship of eco-friendly attitudes with walking and biking to work," Journal of Public Health Management and Practice, vol. 17, no. 5, pp. E9E17, 2011.

[36] U. Eriksson, D. Arvidsson, K. Gebel, H. Ohlsson, and K. Sundquist, "Walkability parameters, active transportation and objective physical activity: moderating and mediating effects of motor vehicle ownership in a cross-sectional study," International Journal of Behavioral Nutrition and Physical Activity, vol. 9, p. 123, 2012.

[37] A. T. Kaczynski, M. J. Bopp, and P. Wittman, "Association of workplace supports with active commuting," Preventing chronic disease, vol. 7, no. 6, p. A127, 2010.

[38] D. Ogilvie, R. Mitchell, N. Mutrie, M. Petticrew, and S. Platt, "Personal and environmental correlates of active travel and physical activity in a deprived urban population," International Journal of Behavioral Nutrition and Physical Activity, vol. 5, article no. 43, 2008.

[39] S. Titze, B. Giles-Corti, M. W. Knuiman et al., "Associations between intrapersonal and neighborhood environmental characteristics and cycling for transport and recreation in adults: baseline results from the RESIDE study," Journal of Physical Activity and Health, vol. 7, no. 4, pp. 423-431, 2010.

[40] G. S. Lovasi, O. Schwartz-Soicher, K. M. Neckerman, K. Konty, B. Kerker, J. Quinn et al., "Aesthetic amenities and safety hazards associated with walking and bicycling for transportation in New York city," Annals of Behavioral Medicine, vol. 45, 1, pp. 76-85, 2012.

[41] L. M. Wen, J. Kite, and C. Rissel, "Is there a role for workplaces in reducing employees' driving to work? Findings from a cross-sectional survey from inner-west Sydney, Australia," BMC Public Health, vol. 10, article no. 50, 2010.

[42] L. Yang, J. Panter, S. J. Griffin, and D. Ogilvie, "Associations between active commuting and physical activity in working adults: cross-sectional results from the commuting and health in Cambridge study," Preventive Medicine, vol. 55, no. 5, pp. 453457, 2012.

[43] L. M. Besser and A. L. Dannenberg, "Walking to public transit: steps to help meet physical activity recommendations," American Journal of Preventive Medicine, vol. 29, no. 4, pp. 273280, 2005.

[44] S. Sahlqvist, Y. Song, and D. Ogilvie, "Is active travel associated with greater physical activity? The contribution of commuting and non-commuting active travel to total physical activity in adults," Preventive Medicine, vol. 55, no. 3, pp. 206-211, 2012.

[45] A. T. Kaczynski, M. Bopp, and P. Wittman, "To drive or not to drive: factors differentiating active versus non-active commuters," Health Behaviour \& Public Health, vol. 2, no. 2, pp. 14-19, 2012.

[46] W. L. Haskell, I. M. Lee, R. R. Pate et al., "Physical activity and public health: updated recommendation for adults from the American college of sports medicine and the American heart association," Medicine and Science in Sports and Exercise, vol. 39, no. 8, pp. 1423-1434, 2007.

[47] C. L. Blue, D. G. Marrero, and D. R. Black, "Physical activity belief scales for diabetes risk: development and psychometric testing," Health Education and Behavior, vol. 35, no. 3, pp. 316331, 2008.

[48] K. Radhakrishnan, "The efficacy of tailored interventions for self-management outcomes of type 2 diabetes, hypertension or heart disease: a systematic review," Journal of Advanced Nursing, vol. 68 , no. 3, pp. 496-510, 2012.

[49] J. de Flines and A. J. Scheen, "Management of metabolic syndrome and associated cardiovascular risk factors," Acta Gastro-Enterologica Belgica, vol. 73, no. 2, pp. 261-266, 2010.

[50] L. Angermayr, D. Melchart, and K. Linde, "Multifactorial lifestyle interventions in the primary and secondary prevention of cardiovascular disease and type 2 diabetes mellitus-a systematic review of randomized controlled trials," Annals of Behavioral Medicine, pp. 1-16, 2010.

[51] C. W. Shepherd and A. E. While, "Cardiac rehabilitation and quality of life: a systematic review," International Journal of Nursing Studies, vol. 49, no. 6, pp. 755-771, 2012.

[52] D. L. Braverman, "Cardiac rehabilitation: a contemporary review," American Journal of Physical Medicine and Rehabilitation, vol. 90, no. 7, pp. 599-611, 2011.

[53] S. I. Mishra, N. M. Aziz, R. W. Scherer, C. R. Baquet, D. R. Berlanstein, and P. M. Geigle, "Exercise interventions on health related quality of life for cancer survivors," Cochrane Database of Systematic Reviews, vol. 8, no. 1, Article ID CD007566, 2009.

[54] F. D. Barber, "Social support and physical activity engagement by cancer survivors," Clinical Journal of Oncology Nursing, vol. 16, no. 3, pp. E84-E98, 2012.

[55] J. F. Sallis, L. D. Frank, B. E. Saelens, and M. K. Kraft, "Active transportation and physical activity: opportunities for collaboration on transportation and public health research," Transportation Research A, vol. 38, no. 4, pp. 249-268, 2004.

[56] A. E. Bauman, R. S. Reis, J. F. Sallis, J. C. Wells, R. J. Loos, and B. W. Martin, "Correlates of physical activity: why are some people physically active and others not?" The Lancet, vol. 380, no. 9838, pp. 258-271, 2012.

[57] D. Berrigan, R. P. Troiano, T. McNeel, C. DiSogra, and R. Ballard-Barbash, "Active transportation increases adherence to activity recommendations," American Journal of Preventive Medicine, vol. 31, no. 3, pp. 210-216, 2006.

[58] J. Lopez-Zetina, H. Lee, and R. Friis, “The link between obesity and the built environment. Evidence from an ecological analysis of obesity and vehicle miles of travel in California," Health and Place, vol. 12, no. 4, pp. 656-664, 2006.

[59] U. Lachapelle, L. Frank, B. E. Saelens, J. F. Sallis, and T. L. Conway, "Commuting by public transit and physical activity: where you live, where you work, and how you get there," Journal of Physical Activity \& Health, vol. 8, pp. S72-S82, 2011.

[60] U. Lachapelle and L. D. Frank, "Transit and health: mode of transport, employer-sponsored public transit pass programs, and physical activity," Journal of Public Health Policy, vol. 30, supplement 1, pp. S73-S94, 2009. 
[61] E. Hansson, K. Mattisson, J. Bjork, P. O. Ostergren, and K. Jakobsson, "Relationship between commuting and health outcomes in a cross-sectional population survey in southern Sweden," BMC Public Health, vol. 11, article 834, 2011.

[62] E. Hemmingsson, U. Ekelund, and J. Udden, "Bicycling but not walking is independently associated with fasting insulin in abdominally obese women," Journal of Physical Activity and Health, vol. 8, no. 6, pp. 820-823, 2011.

[63] L. D. Frank, M. A. Andresen, and T. L. Schmid, "Obesity relationships with community design, physical activity, and time spent in cars," American Journal of Preventive Medicine, vol. 27, no. 2, pp. 87-96, 2004.

[64] A. Morabia, F. E. Mirer, T. M. Amstislavski et al., "Potential health impact of switching from car to public transportation when commuting to work," American Journal of Public Health, vol. 100, no. 12, pp. 2388-2391, 2010.

[65] Y. Zheng, "The benefit of public transportation: physical activity to reduce obesity and ecological footprint," Preventive Medicine, vol. 46, no. 1, pp. 4-5, 2008.

[66] R. Steinbach, J. Green, and P. Edwards, "Look who's walking: social and environmental correlates of children's walking in London," Health Place, vol. 18, no. 4, pp. 917-927, 2012.

[67] J. A. Mendoza, K. Watson, T. Baranowski, T. A. Nicklas, D. K. Uscanga, N. Nguyen et al., "Ethnic minority children's active commuting to school and association with physical activity and pedestrian safety behaviors," Journal of Applied Research on Children, vol. 1, no. 1, pp. 1-23, 2010.

[68] N. C. McDonald, E. Deakin, and A. E. Aalborg, "Influence of the social environment on children's school travel," Preventive Medicine, vol. 50, supplement 1, pp. S65-S68, 2010.

[69] A. E. Mathews, N. Colabianchi, B. Hutto, D. M. Pluto, and S. P. Hooker, "Pedestrian activity among California adults," Journal of Physical Activity and Health, vol. 6, no. 1, pp. 15-23, 2009.

[70] T. G. Ceaser, E. C. Fitzhugh, D. L. Thompson, and D. R. Bassett Jr., "Association of physical activity, fitness, and race: NHANES 1999-2004," Medicine and Science in Sports and Exercise, 2012.

[71] C. J. Crespo, E. Smit, R. E. Andersen, O. Carter-Pokras, and B. E. Ainsworth, "Race/ethnicity, social class and their relation to physical inactivity during leisure time: results from the Third National Health and Nutrition Examination Survey, 1988-1994," American Journal of Preventive Medicine, vol. 18, no. 1, pp. 46$53,2000$.

[72] S. H. Lee and E. O. Im, "Ethnic differences in exercise and leisure time physical activity among midlife women," Journal of Advanced Nursing, vol. 66, no. 4, pp. 814-827, 2010.

[73] D. X. Marquez, C. J. Neighbors, and E. E. Bustamante, "Leisure time and occupational physical activity among racial or ethnic minorities," Medicine and Science in Sports and Exercise, vol. 42, no. 6, pp. 1086-1093, 2010.

[74] S. J. Marshall, D. A. Jones, B. E. Ainsworth, J. P. Reis, S. S. Levy, and C. A. Macera, "Race/ethnicity, social class, and leisure-time physical inactivity," Medicine and Science in Sports and Exercise, vol. 39, no. 1, pp. 44-51, 2007.

[75] F. Müller-Riemenschneider, T. Reinhold, and S. N. Willich, "Cost-effectiveness of interventions promoting physical activity," British Journal of Sports Medicine, vol. 43, no. 1, pp. 70-76, 2009.

[76] J. Chau, Evidence Module: Workplace Physical Activity and Nutrition Interventions, Physical Activity Nutrition and Obesity Research Group, University of Sydney, 2009.
[77] K. I. Proper, M. C. de Bruyne, V. H. Hildebrandt, A. J. van der Beek, W. J. Meerding, and W. van Mechelen, "Costs, benefits and effectiveness of worksite physical activity counseling from the employer's perspective," Scandinavian Journal of Work, Environment and Health, vol. 30, no. 1, pp. 36-46, 2004.

[78] L. M. Anderson, T. A. Quinn, K. Glanz et al., "The effectiveness of worksite nutrition and physical activity interventions for controlling employee overweight and obesity. A systematic review," American Journal of Preventive Medicine, vol. 37, no. 4, pp. 340-357, 2009.

[79] K. I. Proper and W. Van Mechelen, Effectiveness and Economic Impact of Worksite Interventions to Promote Physical Activity and Healthy Diet, World Health Organization, Geneva, Switzerland, 2008.

[80] M. Bopp, A. T. Kaczynski, and M. E. Campbell, "Social ecological influences on work-related active commuting among adults," American Journal of Health Behavior, vol. 37, no. 4, pp. 543-554, 2013.

[81] C. M. Kelly, M. Schootman, E. A. Baker, E. K. Barnidge, and A. Lemes, "The association of sidewalk walkability and physical disorder with area-level race and poverty," Journal of Epidemiology and Community Health, vol. 61, no. 11, pp. 978-983, 2007.

[82] T. Hinrichs and M. Brach, “The general practitioner's role in promoting physical activity to older adults: a review based on program theory," Current Aging Science, vol. 5, no. 1, pp. 41-50, 2012.

[83] J. O. Crawford, R. A. Graveling, H. A. Cowie, and K. Dixon, "The health safety and health promotion needs of older workers," Occupational Medicine, vol. 60, no. 3, pp. 184-192, 2010.

[84] E. V. Cyarto, G. E. Moorhead, and W. J. Brown, "Updating the evidence relating to physical activity intervention studies in older people," Journal of Science and Medicine in Sport, vol. 7, no. 1, pp. 30-38, 2004.

[85] A. C. King, "Interventions to promote physical activity by older adults," The Journals of Gerontology A, vol. 56, no. 2, pp. 36-46, 2001.

[86] V. S. Conn, M. A. Minor, K. J. Burks, M. J. Rantz, and S. H. Pomeroy, "Integrative review of physical activity intervention research with aging adults," Journal of the American Geriatrics Society, vol. 51, no. 8, pp. 1159-1168, 2003.

[87] A. E. Bauman, J. F. Sallis, D. A. Dzewaltowski, and N. Owen, "Toward a better understanding of the influences on physical activity: the role of determinants, correlates, causal variables, mediators, moderators, and confounders," American Journal of Preventive Medicine, vol. 23, no. 2, pp. 5-14, 2002. 


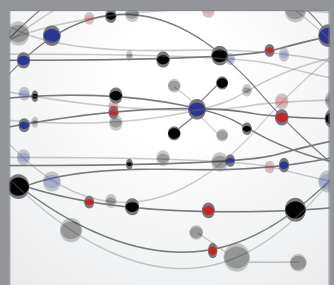

The Scientific World Journal
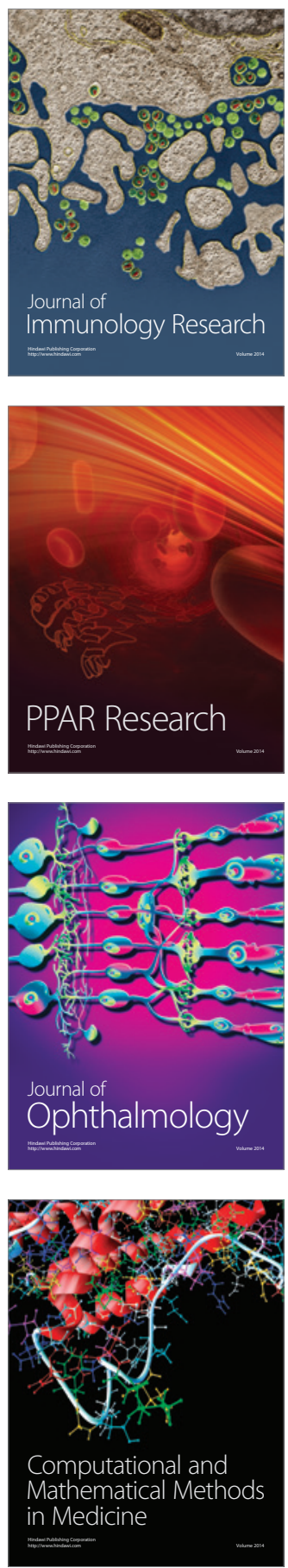

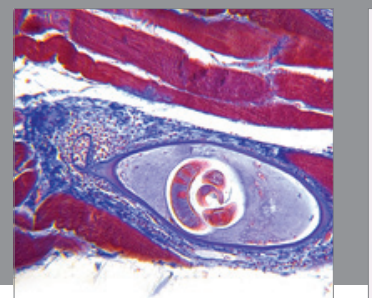

Gastroenterology

Research and Practice


\section{Hindawi}

Submit your manuscripts at

http://www.hindawi.com
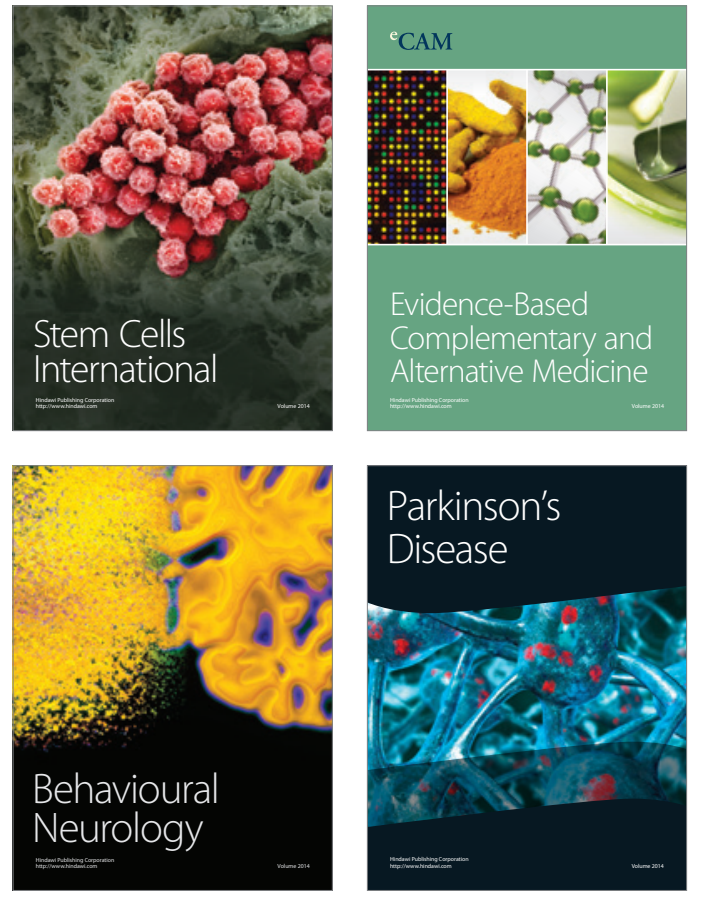
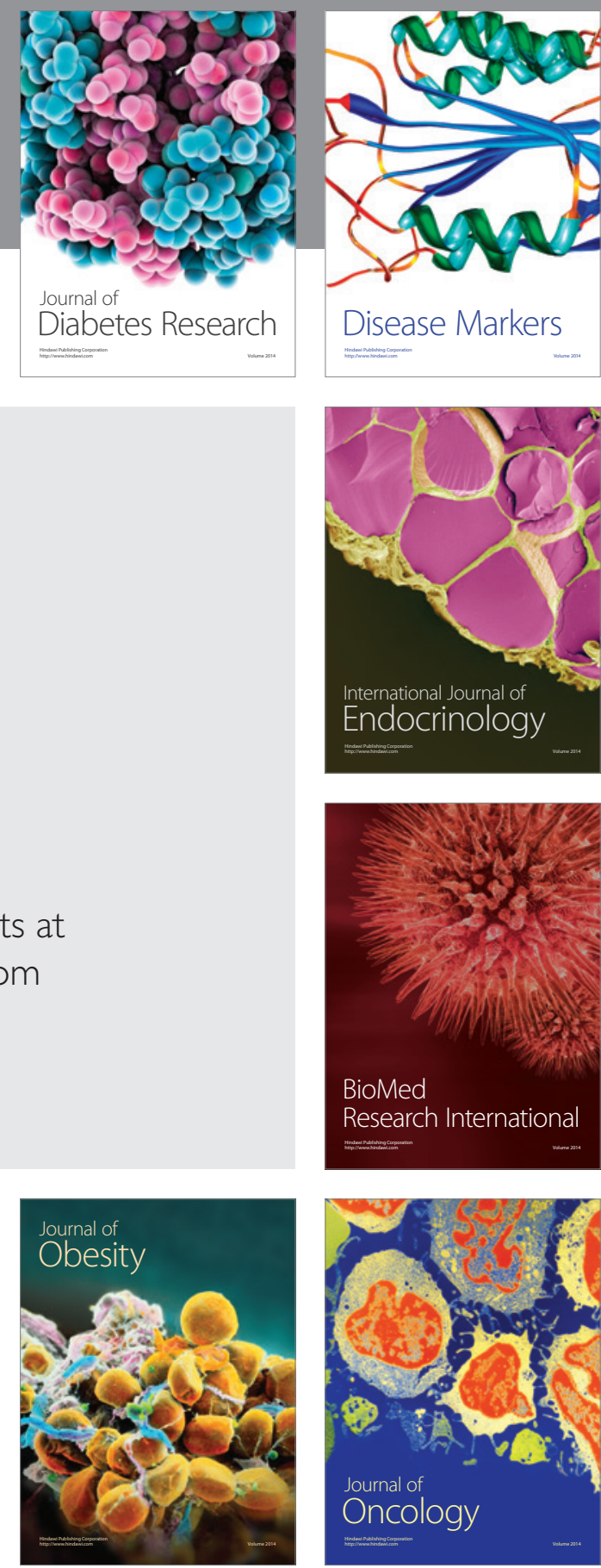

Disease Markers
